majority of civilized mankind. The frequent occurrence of these reflexes and, especially, the frequent occurrence of differentiation must result in an increase in the amount of cortical inhibition occurring in most people. The case of the automobile driver is chosen as an example to demonstrate concretely the validity of these statements. It is to these circumstances that one may plausibly attribute the vast increase in the incidence of narcolepsy in the past two decades.

\title{
REFERENGES
}

1 Harding, G. T., and Berg, T., ' Narcolepsy,' Ohio State Med. Jour., 1932, 28, 581.

${ }^{2}$ LEvin, M., ' The pathogenesis of narcolepsy, with a consideration of sleep-paralysis and localized sleep,' Jour. Neurol. and Psychopath., 1933, 14, 1.

${ }^{3}$ LEvin, M., 'Military aspects of narcolepsy, with remarks on the pathogenesis of narcolepsy and on fatigue,' ibid., 1933, 14, 124.

4 Spiller, W. G., ' Narcolepsy occasionally a postencephalitic syndrome,' Jour. Amer. Med. Assoc., 1926, 86, 673.

5 Wilson, S. A. K., ' The narcolepsies,' Brain, 1928, 51, 63.

\section{SUPPLEMENTARY NOTE}

After this article was accepted by the Editor of the Journal, I came across a recent article by M. S. Kaplinski ('Anfälle von kurzweiligem Einschlafen bei Transportführern,' Zeits.f. d. g. Neurol. u. Psychiat., 1933, 147, 101). Kaplinski calls attention to the frequency with which sleep attacks occur in chauffeurs and street-car motormen. This frequency is so great that the authorities of the Moscow street railways have asked the Institute for Industrial Hygiene to make a study of the matter - a fact of great interest in view of the discussion offered in my paper.

On one point I must disagree with Kaplinski. In explaining the sleep attacks occurring in drivers of vehicles, he alludes to the fact that passengers frequently fall asleep, seemingly through the influence of the monotonous sounds and rockings of a moving conveyance. He clearly implies (in several places) that the somnolence of the driver is brought on by the same monotony which lulls the passenger to sleep. But, instead of being comparable, the situations of the passenger and the driver differ tremendously in their physiological import. The passenger relaxes; he makes no effort to 'take in ' stimuli. The driver, on the other hand, 'strains his attention' to the utmost ; he strives to see and hear everything, and, as I have already tried to show, there is in his case continual differentiation of positive and negative stimuli. I am not prepared to formulate the causes of the somnolence that overtakes the passenger, but, whatever they are, I should for the present regard them as negligible in their bearing on the somnolence of the driver. 